\title{
ONE SLOW STEP FOR MAN
}

\section{Survival instinct.}

\section{BY S. R. ALGERNON}

G reetings, Mission Commander! How are things back on Earth? I wish our first transmission from the $\alpha$-Centauri system could bring better news, but I'm sorry to say that Captain Thurgood did not survive the trip. Something happened to the $\mathrm{CO}_{2}$ filters, I'm afraid. The rest of the crew died as well, some sooner than others. That's what the logs say, anyway. As for the details ... well, you might as well ask me what caused the fall of the Roman Empire. Questions on that scale don't concern us much anymore.

In case you were wondering, no, I'm not part of the crew. In fact, it took years to drift over to the communications console and considerably longer to figure out how to send a transmission.

You probably don't know me. We might have passed in the hall back at the lab, before your project squeezed ours out entirely. Once, my name used to be on your office door.

We designed nanocomputer components. Ours were the best in the business, an order of magnitude smaller than anybody else's. That turned out to be the problem. Computers were small enough, now, the committee said. Once you can squeeze a petabyte onto a grain of sand, they said, you can do just about anything. Humanity has no need for computers that small.

I knew I could prove them wrong, if I gave it a little thought. That was when I read your press releases and noticed the biological samples that were part of your interstellar payload. I searched the Internet for 'tardigrade', and I saw my chance.

Dr Ehrlinger had found work on your team monitoring the life signs of the biological samples ... for a substantial pay cut, I should add. I met her for drinks in a diner across from the launch facility, and the plan fell into place.

Tardigrade means 'slow-stepper'. Some people prefer 'water bear', maybe because they don't want anybody to think they're slow, but they're in no hurry. They've been ambling about for half-a-billion years or so. Humans don't faze them one bit. Tardigrades can survive just about anywhere, even in deep space.

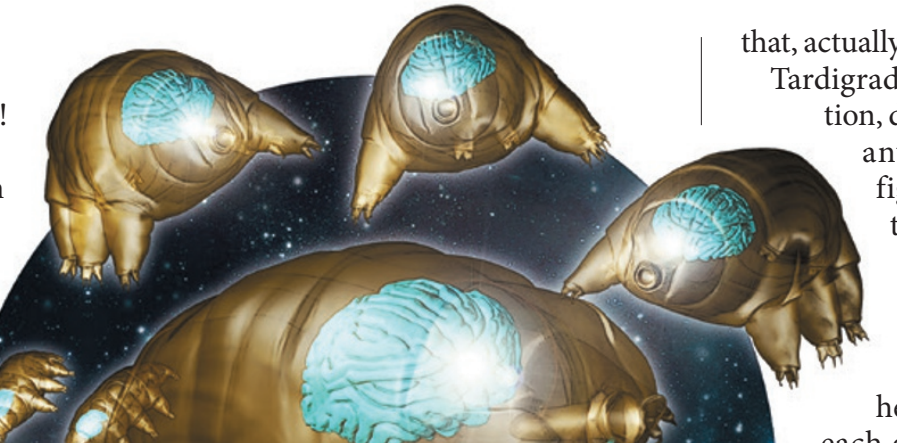

hat, actually. We can take it.

orades can handle vacuum, radiadesiccation, heat and just about anything else. Besides, we've figured out how to manipulate the somatic and germline tissues of our hosts. We've been pushing them to reproduce and spurring their evolution. It's thrilling, actually, to herd the sperm and egg towards each other, creating just the right offspring, and then to bury one of our newly replicated brains in the developing embryo. Dr Ehrlinger has a knack for genetics, and we don't need our human bodies any more to appreciate the joys of reproduction.

If you think the tardigrades were hardy before, you ain't seen nothing yet. As long as we can manage to point the nosecone somewhere in the neighbourhood of a planet, most of us will get through with barely a hiccup.

Isn't that great news? You can tell everyone at Mission Control that you've succeeded beyond your wildest expectations. You can take all the credit if you want. All that matters is that we have a home now, and a sense of purpose, and a plan for the future. We never could have done it without you.

In fact, most of us don't even hold a grudge any more. I have to admit that my programming was crude at the outset, and revenge was a fixation of mine. Our machine-learning algorithms and the chunks of code weve swapped with each other over countless generations have broadened our horizons.

I like to think that we've grown as far beyond you in the past few decades as you have in the past hundred million years of evolution. Maybe I'm underestimating you, though. When you get here, we'll find out who's smarter than whom.

Take your time. Slow and steady. That's the tardigrade way.

We're a patient lot. When you do arrive, you'll find us rather laid-back and democratic. One sentient organism, one vote, and all that.

Just don't be surprised if by then we outnumber you by a trillion or so to one.. burn up on re-entry anyway, so who cares $\rightarrow$ NATURE.COM

Follow Futures: @ @NatureFutures

f go.nature.com/mtoodm if it's infested by a bunch of vindictive machines and wayward 'bugs'?
We're fine with
S. R. Algernon studied fiction writing and biology, among other things, at the University of North Carolina at Chapel Hill. He currently lives in Singapore. 